Louisiana State University

LSU Digital Commons

Faculty Publications

Department of Biological Sciences

8-1-2013

\title{
Marital satisfaction and depressive symptoms in China
}

Richard B. Miller

Brigham Young University

Tiffany M. Mason

Brigham Young University

Jerevie M. Canlas

Brigham Young University

Dahua Wang

Beijing Normal University

David A. Nelson

Brigham Young University

See next page for additional authors

Follow this and additional works at: https://digitalcommons.Isu.edu/biosci_pubs

\section{Recommended Citation}

Miller, R., Mason, T., Canlas, J., Wang, D., Nelson, D., \& Hart, C. (2013). Marital satisfaction and depressive symptoms in China. Journal of Family Psychology, 27 (4), 677-682. https://doi.org/10.1037/a0033333

This Article is brought to you for free and open access by the Department of Biological Sciences at LSU Digital Commons. It has been accepted for inclusion in Faculty Publications by an authorized administrator of LSU Digital Commons. For more information, please contact ir@lsu.edu. 


\section{Authors}

Richard B. Miller, Tiffany M. Mason, Jerevie M. Canlas, Dahua Wang, David A. Nelson, and Craig H. Hart 


\section{Marital Satisfaction and Depressive Symptoms in China}

Richard B. Miller

Brigham Young University - Provo, rick_miller@byu.edu

Tiffany M. Mason

Brigham Young University - Provo

Jerevie M. Canlas

Brigham Young University - Provo

Dahua Wang

Beijing Normal University

David A. Nelson

Brigham Young University - Provo

See next page for additional authors

Follow this and additional works at: https://scholarsarchive.byu.edu/facpub

Part of the Family, Life Course, and Society Commons, and the Sociology of Culture Commons

\section{BYU ScholarsArchive Citation}

Miller, Richard B.; Mason, Tiffany M.; Canlas, Jerevie M.; Wang, Dahua; Nelson, David A.; and Hart, Craig H., "Marital Satisfaction and Depressive Symptoms in China" (2013). Faculty Publications. 3961.

https://scholarsarchive.byu.edu/facpub/3961

This Peer-Reviewed Article is brought to you for free and open access by BYU ScholarsArchive. It has been accepted for inclusion in Faculty Publications by an authorized administrator of BYU ScholarsArchive. For more information, please contact scholarsarchive@byu.edu, ellen_amatangelo@byu.edu. 


\section{Authors}

Richard B. Miller, Tiffany M. Mason, Jerevie M. Canlas, Dahua Wang, David A. Nelson, and Craig H. Hart 


\title{
BRIEF REPORT
}

\section{Marital Satisfaction and Depressive Symptoms in China}

\author{
Richard B. Miller, Tiffany M. Mason, \\ and Jerevie M. Canlas \\ Brigham Young University
}

\author{
Dahua Wang \\ Beijing Normal University
}

\author{
David A. Nelson and Craig H. Hart \\ Brigham Young University
}

\begin{abstract}
Although there is substantial evidence that low marital satisfaction is a significant risk factor for depression, little research has examined this relationship in cultures outside of the U.S. and Europe. The validity of the marital discord model of depression in Chinese culture was tested by studying 391 couples living in Beijing and Hangzhou, China. Results of structural equation modeling using an actor-partner interdependence model strategy indicated that husbands' and wives' marital satisfaction was significantly predictive of their own depressive symptoms. In addition, wives' marital satisfaction significantly predicted husbands' depressive symptoms. These results provide evidence that the marital discord model of depression is useful in understanding the role of marital dissatisfaction as a risk factor for depressive symptoms in collectivistic societies, such as China.
\end{abstract}

Keywords: marital discord, depression, China, cross-cultural

The marital discord model of depression theorizes that marital discord is a significant risk factor for depression (Beach, Sandeen, \& O'Leary, 1990). Although the authors acknowledge that the etiology of depression is typically multifaceted, they argue that marital distress can precipitate depression in two ways. First, spouses in distressed marriages generally give and receive less social support in their relationships, which puts them at higher risk for depression. Second, distressed relationships often have higher levels of hostility, which is also predictive of depression.

Research has consistently found that marital distress is a significant predictor of depressive symptoms (Beach, Katz, Kim, \& Brody, 2003; Whisman, 2007; Whisman \& Baucom, 2012; Whitton, Stanley, Markman, \& Baucom, 2008). Despite the robust empirical support for the marital discord model of depression using U.S. and European samples (Overbeek et al., 2006; Whisman \& Uebelacker, 2009), the model has been largely untested in other cultures. Specifically, it is unclear if the model is applicable in collectivist societies, where cultural values center on broader family and societal well-being. To date, only two studies have

This article was published Online First July 8, 2013.

Richard B. Miller, Tiffany M. Mason, and Jerevie M. Canlas, School of Family Life, Brigham Young University; Dahua Wang, School of Psychology, Beijing Normal University, Beijing, China; David A. Nelson and Craig H. Hart, School of Family Life, Brigham Young University.

Correspondence concerning this article should be addressed to Richard B. Miller, School of Family Life, Brigham Young University, Provo, UT, 84602. E-mail: rick_miller@byu.edu examined the relationship between marital distress and depressive symptoms in collectivist societies. One study was conducted in southern Brazil and found that marital dissatisfaction predicted depressive symptoms among 99 women two years later, controlling for initial levels of depression (Hollist, Miller, Falceto, \& Fernandes, 2007). The other study was conducted in Singapore and found that marital dissatisfaction was predictive of concurrent depressive symptoms among 1,026 individuals (Sandberg, Yorgason, Miller, \& Hill, 2012).

At a conceptual level, this issue evokes cross-cultural psychology's "emic-etic" dichotomy (Nelson et al., 2006; Berry, 1989). An "emic" approach assumes that cultural values substantially influence family processes, which suggests that family processes, and their effect on family members' well-being, need to be studied and interpreted within specific cultures. On the other hand, an "etic" approach assumes that family processes are similar across cultures and compares behaviors found in one culture with another culture using similar assumptions and measures.

Historically, China represents a culture with a long tradition of collectivism. Families in China have traditionally been patriarchal and hierarchal (Pimentel, 2000). Parent-child relationships have been considered more important than marital relationships, and the head of the household typically made all of the family decisions, supported by his sons and their families (Lu \& Lin, 1998). Arranged marriages by parents were the norm (Wolf \& Gates, 1998), and the marital relationship was viewed as a means of connecting families and perpetuating the family lineage; its focus was more on function than on affection.

The Chinese government has substantially changed the structure and function of Chinese families, beginning with the 1950 mar- 
riage law. The effect of these changes has been to promote individual marriage choice and to increase the equality of women in families, as well as in society (Hershatter, 2004). Subsequent laws have further strengthened the position of women in marriage and established more liberal divorce laws. Gradually, the purpose of marriage, especially in urban areas, has shifted from utility and responsibility toward mutual respect, admiration, and an expression of love between individuals (Chen \& Li, 2007; Guo \& Huang, 2005).

Despite these changes, China remains a strong collectivist society. With China having the largest population in the world, it is an ideal setting to test the validity of the marital discord model of depression in a collectivistic society. The purpose of this study was to examine the relationship between marital satisfaction and depressive symptoms using a sample of couples living in Beijing and Hangzhou, China.

\section{Marital Satisfaction and Depression in China}

There is some evidence that marital quality is associated with life satisfaction and personal well-being among Chinese couples. A series of studies by D. T. L. Shek using samples in Hong Kong have found an association between marital quality and personal well-being. In 1995, he sampled 1,499 men and women to study the impact of marital quality on well-being among Chinese married adults (Shek, 1995). He found that marital quality was significantly associated with personal well-being. In another study that used longitudinal data, Shek (2000) studied 378 Chinese families and found that marital quality predicted personal well-being, life satisfaction, and health two years later. Although these studies provide evidence that marital quality is a significant predictor of personal well-being, they did not specifically measure depressive symptoms.

\section{Gender and Partner Effects}

Some scholars have theorized that the association between marital distress and depressive symptoms would be greater among women than men (Beach et al., 2003; Fincham, Beach, Harold, \& Osborne, 1997). Although some research has found that the relationship between marital distress and depressive symptoms is stronger for women (Fincham et al., 1997), the bulk of studies have found no gender differences (Beach et al., 2003; Whisman, 2007; Whisman \& Uebelacker, 2009), including the study conducted in Singapore (Sandberg et al., 2012).

Most of the research on marital distress and depression has examined the effect of marital distress on one's own depressive symptoms (Whisman \& Baucom, 2012). However, the marital discord model of depression suggests that a spouse's marital distress creates less support and more hostility in the relationship, which puts the other spouse at increased risk to experience depressive symptoms. Thus, it is important to test the cross-spouse effect of marital distress on depressive symptoms (Whisman, Uebelacker, \& Weinstock, 2004). The actor-partner interdependence model (APIM; Kenny, Kashy, \& Cook, 2006) fully utilizes dyadic data by allowing an examination of spouses' marital distress on their own depressive symptoms (actor effects), as well as on their spouses' depressive symptoms (partner effects). APIM is designed with the assumption that the scores of two "linked" individuals are correlated, thus suggesting that one person's score can provide information about the other person's score. Consequently, it is appropriate to consider the scores as interdependent (Kenny et al., 2006).

Previous research on partner effects in the predictive relationship between marital distress and depressive symptoms has been mixed. Although Whisman and associates (2004) and Beach and associates (2003) found significant partner effects, Whisman and Uebelacker (2009) reported that the relationship between marital distress and partner's subsequent depressive symptoms was not significant.

In summary, there have been no direct tests of the marital discord model of depression among Chinese couples. This study tested the hypothesis that marital satisfaction will be negatively predictive of depressive symptoms among Chinese husbands and wives.

\section{Method}

\section{Sample}

All of the parents in the study were married, and all of them were ethnic Chinese. The mothers' and fathers' mean ages were $32.91(S D=3.35)$ and $35.14(S D=3.77)$, respectively. The age of the mothers ranged from 25 to 47 years, and the fathers' ages ranged from 25 to 52 years. Mothers had an average of 13.28 $(S D=2.63)$ years of education, while the fathers had an average of $13.75(S D=2.80)$ years of education.

\section{Procedure}

The data used for this study were collected in Beijing and Hangzhou, China between 1995 and 2001 (Nelson et al., 2006). The sample consisted of 467 parent couples with children enrolled in five preschools, four in Beijing and one in Hangzhou. Both are large urban centers; Beijing, located in northeastern China, is the capital city of China, and Hangzhou, located in east central China, is the capital city of Zhejiang Province. After approval from the lead author's university institutional review board, data were collected from families who had children attending one of the preschools. School administrators arranged meetings between the researchers and the parents so that specific instructions could be explained to the parents. Parents were told that their participation was voluntary, and that they could withdraw at any time from the study. They were assured that their responses would be kept confidential. Because of the large number of questions, the overall questionnaire was divided into three packets. The parents took one packet home at a time and returned each packet on a weekly basis. Each of the packets took approximately 30-45 minutes to complete. Overall, $70 \%$ of the families in the five preschool classes participated in the study. All of the measures in the questionnaires were carefully forward- and back-translated and pilot-tested with Chinese parents (Nelson et al., 2006). When data for the variables used in these analyses were missing, maximum likelihood estimates were employed to estimate parameters using the statistical software AMOS, assuming that the missing data were missing at random (Arbuckle, 2007). 


\section{Measures}

Marital satisfaction. Marital satisfaction was measured using the Kansas Marital Satisfaction Scale (KMSS), which is a widely used scale that measures partners' ratings of their level of satisfaction with the marriage, relationship, and spouse. The items are measured on a Likert-type scale ranging from 1 (not very satisfied) to 5 (very satisfied). Previous research has found that the scale is reliable, with a Cronbach's alpha of .96 , and it can differentiate distressed and nondistressed couples (Schumm et al., 1986).

Chinese researchers have created a Chinese version of the Kansas Marital Satisfaction Scale and found adequate reliability and validity properties of the scale (Shek, Lam, Tsoi, \& Lam, 1993). The scale is highly correlated with Chinese versions of the Dyadic Adjustment Scale and the Marital Comparison Level Index. The scale differentiates satisfied and dissatisfied couples and has a Cronbach's alpha of .97 , demonstrating high reliability of items. The KMSS for men and women in this sample had a Cronbach's alpha of .92 and .91 , respectively.

Depressive symptoms. Depressive symptoms were measured using the 20-item Center for Epidemiological Studies-Depression Scale (CES-D). Each question was measured on a Likert-type scale ranging from 0 (rarely or none of the time) to 3 (most or all of the time). Previous studies have found the CES-D to be a valid and reliable measure of depressive symptoms (Radloff, 1977). A Chinese version of the CES-D was found to be reliable, with Cron- bach's alpha scores of .83 for men and .82 for women (Cheung \& Bagley, 1998). Tests of validity indicated that the Chinese CES-D was negatively correlated with life satisfaction and positively correlated with stressful life events. The CES-D for men and women in this sample had a Cronbach's alpha of .76 and .74, respectively.

Control variables. Control variables included years of education and age of each parent and data collection site identification. They were measured using standard demographic questions.

\section{Analysis}

Figure 1 represents the path model that was analyzed in this study. The dyadic data were fully utilized by using an APIM strategy (Kenny et al., 2006). Structural equation modeling (SEM) was used to analyze the path model, and the statistical program, AMOS (Arbuckle, 2007), was used to conduct the analysis. The primary advantage of SEM is that it controls for measurement error, which reduces bias in the regression coefficients (Kline, 2010).

\section{Results}

\section{Preliminary Analyses}

The mean score of marital satisfaction for husbands and wives was $4.09(S D=.95)$ and $3.91(S D=.98)$, respectively. The mean

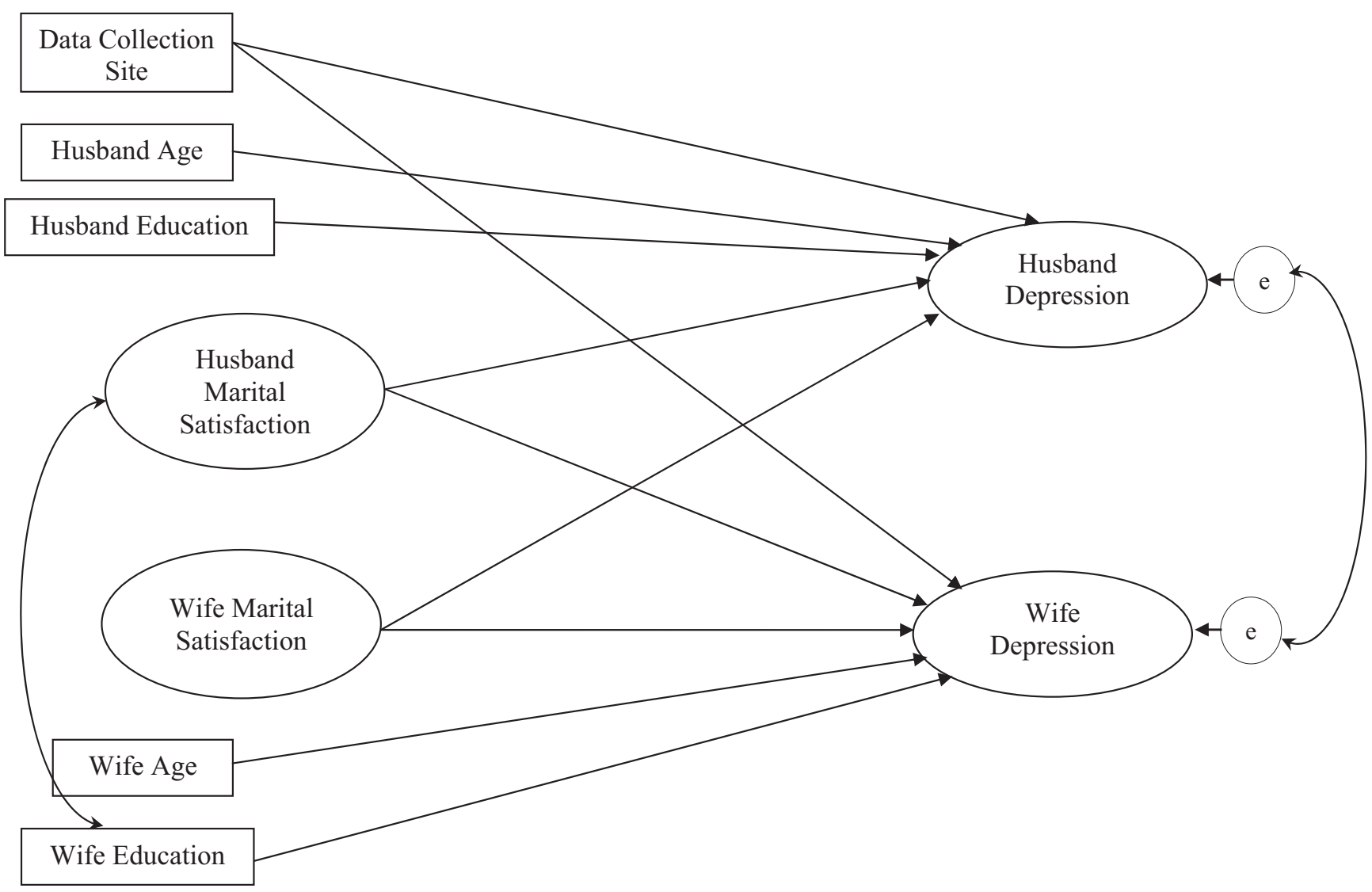

Figure 1. Structural model for husbands' and wives' marital satisfaction and depressive symptoms, controlling for age, education, and data collection site. 
Table 1

Correlations Among Marital Satisfaction, Depressive Symptoms, Age, Collection Site, and Education

\begin{tabular}{|c|c|c|c|c|c|c|c|c|c|c|}
\hline Variable & Mean $(S D)$ & 1 & 2 & 3 & 4 & 5 & 6 & 7 & 8 & 9 \\
\hline 1. Husband age & $35.14(3.77)$ & - & & & & & & & & \\
\hline 2. Husband education & $13.75(2.80)$ & $.17^{* *}$ & - & & & & & & & \\
\hline 3. Wife age & $32.91(3.35)$ & $.78^{* *}$ & $.17^{* * *}$ & - & & & & & & \\
\hline 4. Wife education & $13.28(2.63)$ & $.21^{* *}$ & $.65^{* *}$ & $.25^{* *}$ & - & & & & & \\
\hline 5. Data collection site & & -.08 & $-.12^{*}$ & $-.17^{* *}$ & $-.24^{* *}$ & - & & & & \\
\hline 6. Husband marital satisfaction & $4.09(.95)$ & -.07 & .01 & -.01 & .03 & $.10^{*}$ & - & & & \\
\hline 7. Wife marital satisfaction & $3.91(.98)$ & -.07 & .06 & -.07 & .01 & .08 & $-.44^{* *}$ & - & & \\
\hline 8. Husband depression & $8.24(1.74)$ & -.02 & $-.11^{*}$ & .04 & -.01 & $-.18^{* *}$ & $-.22^{* *}$ & $-.18^{* *}$ & - & \\
\hline 9. Wife depression & $8.46(1.95)$ & -.07 & -.03 & -.03 & -.03 & $-.16^{* *}$ & $-.20^{* *}$ & $-.31^{* *}$ & $.32^{* * *}$ & - \\
\hline
\end{tabular}

${ }^{*} p<.05$. $\quad{ }^{* *} p<.001$.

score of depressive symptoms for husbands and wives was 8.24 $(S D=1.74)$ and $8.46(S D=1.95)$, respectively. The results of correlational analysis (see Table 1) indicated that husbands' marital satisfaction was significantly correlated with their own depressive symptoms $(r=-.22, p<.001)$ and their wives' depressive symptoms $(r=-.20, p<.001)$. Wives' marital satisfaction was also negatively correlated with their own depressive symptoms $(r=-.31, p<.001)$ and their husbands' depressive symptoms $(r=-.18, p<.001)$

\section{Path Model Results}

The results of the goodness-of-fit analysis indicated that the model fit the data well. The $\chi^{2}$ was 280.71 , with $124 d f$, which is an acceptable ratio. The cumulative fit index (CFI) was .96 , and the Tucker-Lewis index (TLI) was .94, which are well above the cutoff score of .90 . The root mean square error of approximation (RMSEA) was .05. This model included the control variables of age, education, and data collection site. Running the model without these control variables made the model fit significantly worse $\left(\Delta \chi^{2}=28, d f=6, p<.01\right)$. A separate test was conducted to determine if the inclusion of the data collection site variable was important for good model fit. This model, which included only age and education as control variables, also had a significantly poorer fit than the model with all three control variables $\left(\Delta \chi^{2}=24, d f=2\right.$, $p<.01)$. Consequently, the model that was used in the analysis included age, education, and data collection site as control variables.

As indicated in Table 2, results of the examination of actor effects indicated that the relationship was significant for husbands $(\beta=-.13, p<.05)$ and for wives $(\beta=-.33, p<.01)$. Results of the partner effects indicated that husbands' marital satisfaction did not significantly predict wives' depressive symptoms $(\beta=$ $-.00, p=.97)$, but wives' marital satisfaction significantly predicted husbands' depressive symptoms $(\beta=-.11, p<.05)$. Among the control variables, wives' age was significantly associated with wives' depressive symptoms $(\beta=-.09, p<.05)$, and data collection site was significantly associated with husbands' depressive symptoms $(\beta=-.20, p<.01)$ and wives' depressive symptoms $(\beta=-.16, p<.01)$.

\section{Gender Differences}

In structural equation modeling, equivalence of regression coefficients demonstrates that the latent variables are related in the same way across groups. To test for gender differences in the model, the $\chi^{2}$ difference invariance test was used, which evaluates noninvariance across parameters by comparing the $\chi^{2}$ values of the configural model and other models in which particular parameters are constrained to be equal. According to Byrne (2010), evidence

Table 2

The Effect of Marital Satisfaction on Depressive Symptoms

\begin{tabular}{lccc}
\hline & Unstandardized & Standardized & $p$ \\
\hline Actor effects & & & \\
$\quad$ Husband marital satisfaction $\rightarrow$ Husband & -.45 & -.13 & .02 \\
depression & & & .46 \\
Husband age $\rightarrow$ Husband depression & -.41 & -.03 & .07 \\
Husband education $\rightarrow$ Husband depression & -.03 & -.07 & .00 \\
Collection site $\rightarrow$ Husband depression & -.61 & -.33 & .00 \\
Wife marital satisfaction $\rightarrow$ Wife depression & -.02 & -.09 & .83 \\
Wife age $\rightarrow$ Wife depression & .01 & -.01 & .00 \\
Wife education $\rightarrow$ Wife depression & -.28 & -.00 & .97 \\
Collection site $\rightarrow$ Wife depression & & -.01 & .04 \\
Partner effects & -.41 & & \\
Husband marital satisfaction $\rightarrow$ Wife depression & & & \\
Wife marital satisfaction $\rightarrow$ Husband depression &
\end{tabular}

Note. Model Fit: Chi-square $=280.71(d f=124)$, RMSEA $=.05 ;$ CFI $=.96 ;$ TLI $=.94$. 
of noninvariance is established when the $\chi^{2}$ difference value is statistically significant.

Results of the gender analyses indicated that the effect of both spouses' marital satisfaction on their own depressive symptoms did not differ significantly. The $\chi^{2}$ difference between the unconstrained model and the model where actor effects were constrained to be equal was .93 ( $d f=1, p=.33)$, indicating that there was no difference in the path coefficients between wives' marital satisfaction and their own depressive symptoms and husbands' marital satisfaction and their own depressive symptoms. Constraining the partner effects to be equal resulted in a $\chi^{2}$ difference between the two models that approached significance $\left(\Delta \chi^{2}=3.72, d f=1, p=\right.$ .053 ) but did not meet the standard of statistical significance at the .05 level. Thus, there were no gender differences among the partner effects based on testing the invariance of the paths between marital satisfaction and spouses' depressive symptoms.

\section{Discussion}

The findings of the study support the validity of the marital discord model of depression in China, which is a large, collectivistic society. Consequently, these results, when considered in the context of the studies in Brazil (Hollist et al., 2007) and Singapore (Sandberg et al., 2012), provide support for the "etic" perspective on marital satisfaction and depressive symptoms, with marital distress being a significant predictor of depressive symptoms in both individualistic and collectivistic societies.

These findings that marital distress is a risk factor for depressive symptoms are consistent with a qualitative study that examined the perceived causes of depression among Taiwanese women who had recently recovered from depression ( $\mathrm{Fu} \&$ Parahoo, 2009). The researchers found that marital distress was often perceived as a major cause of their depression. Similar results were found in studies that assessed depressed adults' perceptions of the causes of their depression in Sweden (Hansson, Chotai, \& Bodlund, 2010) and Switzerland (Lauber, Falcato, Nordt, \& Rossler, 2003).

The lack of significant gender differences in the strength of the association between marital satisfaction and one's own depressive symptoms is consistent with previous research. Although theoretical reasons have been postulated to predict a stronger association among women (Fincham et al., 1997), most studies have found no gender differences (Beach et al., 2003; Sandberg et al., 2012; Whisman \& Uebelacker, 2009). Moreover, this lack of evidence for gender differences in the relationship between marital satisfaction and depression symptoms is congruent with a larger research literature that has found no gender differences between marital distress and other psychological disorders, including anxiety disorders, bipolar disorders, and alcohol disorders (Whisman, 2007), as well as physical health status (Umberson, Williams, Powers, Liu, \& Needham, 2006). The results of the present study provide evidence that the lack of gender differences in the relationship between marital distress and individual well-being extends to collectivistic societies.

Results of the partner-effect analysis found that the path between wives' marital satisfaction and husbands' depressive symptoms was significant, but the path between husbands' marital satisfaction and wives' depressive symptoms was not significant. These results, according to the marital discord model of depression (Beach et al., 1990), suggest that marital dissatisfaction among wives in China is accompanied by increased hostility and decreased spousal support, which puts their husbands at greater risk for depressive symptoms. On the other hand, marital dissatisfaction among husbands in China is apparently not accompanied by behaviors that put their wives at greater risk for depressive symptoms. However, the difference in the significance of the partnereffect paths must be tempered by the fact that the formal test of invariance between the two paths only approached statistical significance.

There are two important limitations to this study. First, the data came from two large metropolitan areas of China: Beijing and Hangzhou. These two cities are highly urbanized and the resulting findings from the sample might not reflect family dynamics in rural settings. Because there are substantial cultural differences between urban and rural China (Pimentel, 2000), the generalizability of this study's results are limited.

Second, longitudinal research is needed to better understand the predictive effect of marital satisfaction on subsequent depressive symptoms. With research demonstrating the bidirectionality of the relationship between marital satisfaction and depression (Whisman \& Uebelacker, 2009), it is important to employ longitudinal research to examine the temporal effects of marital satisfaction on depressive symptoms in China.

Overall, the results of this study provide evidence that the marital discord model of depression is a valid model that enables researchers and clinicians to better understand the etiology of depression in China. Combined with the studies of marital satisfaction and depression among Brazilian women (Hollist et al., 2007) and Singaporean married adults (Sandberg et al., 2012), there is emerging evidence that marital dissatisfaction is a significant risk factor for depressive symptoms in collectivist societies.

\section{References}

Arbuckle, J. L. (2007). AMOS (Version 18.0). Chicago, IL: SPSS.

Beach, S., Katz, J., Kim, S., \& Brody, G. H. (2003). Prospective effects of marital satisfaction on depressive symptoms in established marriages: A dyadic model. Journal of Social and Personal Relationships, 20, 355371. doi:10.1177/0265407503020003005

Beach, S., Sandeen, E., \& O'Leary, K. (1990). Depression in marriage. New York, NY: Guilford Press.

Berry, J. W. (1989). Imposed etics-emics-derived etics: The operationalization of a compelling idea. International Journal of Psychology, 24, 721-735. doi:10.1080/00207598908246808

Byrne, B. M. (2010). Structural equation modeling with AMOS (2nd ed.). New York, NY: Routledge.

Chen, F. M., \& Li, T. S. (2007). Marital enqing: An examination of its relationship to spousal contributions, sacrifices, and family stress in Chinese marriages. The Journal of Social Psychology, 147, 393-412. doi:10.3200/SOCP.147.4.393-412

Cheung, C. K., \& Bagley, C. (1998). Validating an American scale in Hong Kong: The Center for Epidemiological Studies Depression Scale (CESD). Journal of Psychology: Interdisciplinary and Applied, 132, 169186. doi:10.1080/00223989809599157

Fincham, F., Beach, S., Harold, G., \& Osborne, L. (1997). Marital satisfaction and depression: Different causal relationships for men and women? Psychological Science, 8, 351-357. doi:10.1111/j.1467-9280 1997.tb00424.X

Fu, C. M., \& Parahoo, K. (2009). Causes of depression among people recovering from depression. Journal of Advanced Nursing, 65, 101-109. doi:10.1111/j.1365-2648.2008.04845.x 
Guo, B., \& Huang, J. (2005). Marital and sexual satisfaction in Chinese families: Exploring the moderating effects. Journal of Sex \& Marital Therapy, 31, 21-29. doi:10.1080/00926230590475224

Hansson, M., Chotai, J., \& Bodlund, O. (2010). Patients' beliefs about the cause of their depression. Journal of Affective Disorders, 124, 54-59. doi:10.1016/j.jad.2009.10.032

Hershatter, G. (2004). State of the field: Women in China's long twentieth century. The Journal of Asian Studies, 63, 991-1065. doi:10.1017/ S0021911804002396

Hollist, C., Miller, R., Falceto, O., \& Fernandes, C. (2007). Marital satisfaction and depression: A replication of the marital discord model in a Latino sample. Family Process, 46, 485-498. doi:10.1111/j.1545-5300 .2007.00227.x

Kenny, D. A., Kashy, D. A., \& Cook, W. L. (2006). Dyadic data analysis. New York, NY: Guilford Press.

Kline, R. (2010). Principles and practice of structural equation modeling (3rd ed.). New York, NY: Guilford Press.

Lauber, C., Falcato, L., Nordt, C., \& Rossler, W. (2003). Lay beliefs about causes of depression. Acta Psychiatrica Scandinavica, 108, 96-99. doi:10.1034/j.1600-0447.108.s418.19.x

Lu, L., \& Lin, Y. Y. (1998). Family roles and happiness in adulthood. Personality and Individual Differences, 25, 195-207. doi:10.1016/ S0191-8869(98)00009-9

Nelson, L., Hart, C., Wu, B., Yang, C., Roper, S., \& Jin, S. (2006). Relations between Chinese mothers' parenting practices and social withdrawal in early childhood. International Journal of Behavioral Development, 30, 261-271. doi:10.1177/0165025406066761

Overbeek, G., Vollebergh, W., de Graff, R., Scholte, R., de Kemp, R., \& Engles, R. (2006). Longitudinal associations of marital quality and marital dissolution with the incidence of $D S M-I I I-R$ disorders. Journal of Family Psychology, 20, 284-291. doi:10.1037/0893-3200.20.2.284

Pimentel, E. E. (2000). Just how do I love thee?: Marital relations in urban China. Journal of Marriage and the Family, 62, 32-47. doi:10.1111/j $.1741-3737.2000 .00032 . x$

Radloff, L. S. (1977). The CES-D Scale: A self-report depression scale for research in the general population. Applied Psychological Measurement, 1, 385-401. doi:10.1177/014662167700100306

Sandberg, J. G., Yorgason, J. B., Miller, R. B., \& Hill, E. J. (2012). Family-to-work spillover in Singapore: Marital distress and instability, physical and mental health, and work satisfaction. Family Relations: An Interdisciplinary Journal of Applied Family Studies, 61, 1-15. doi: 10.1111/j.1741-3729.2011.00682.x
Schumm, W. R., Paff-Bergen, L. A., Hatch, R. C., Obiorah, F. C., Copeland, J. M., Meens, L. D., \& Bugaighis, M. A. (1986). Concurrent and discriminant validity of the Kansas Marital Satisfaction Scale. Journal of Marriage and Family, 48, 381-387. doi:10.2307/352405

Shek, D. T. L. (1995). Gender differences in marital quality and well-being in Chinese married adults. Sex Roles, 32, 699-715. doi:10.1007/ BF01560185

Shek, D. T. L. (2000). Parental marital quality and well-being, parent-child relational quality, and Chinese adolescent adjustment. American Journal of Family Therapy, 28, 147-162. doi:10.1080/019261800261725

Shek, D. T. L., Lam. M. C., Tsoi, K. W., \& Lam, C. M. (1993). Psychometric properties of the Chinese version of the Kansas Marital Satisfaction Scale. Social Behavior and Personality, 21, 241-249. doi:10.2224/ sbp.1993.21.3.241

Umberson, D., Williams, K., Powers, D. A., Liu, H., \& Needham, B. (2006). You make me sick: Marital quality and health over the life course. Journal of Health and Social Behavior, 47, 1-16. doi:10.1177/ 002214650604700101

Whisman, M. A. (2007). Marital distress and DSM-IV psychiatric disorders in a population-based national survey. Journal of Abnormal Psychology, 116, 638-643. doi:10.1037/0021-843X.116.3.638

Whisman, M. A., \& Baucom, D. H. (2012). Intimate relationships and psychopathology. Clinical Child and Family Psychology Review, 15, 4-13. doi:10.1007/s10567-011-0107-2

Whisman, M. A., \& Uebelacker, L. A. (2009). Prospective association between marital discord and depressive symptoms in middle-aged and older adults. Psychology and Aging, 24, 184-189. doi:10.1037/ a0014759

Whisman, M. A., Uebelacker, L. A., \& Weinstock, L. M. (2004). Psychopathology and marital satisfaction: The importance of evaluating both partners. Journal of Consulting and Clinical Psychology, 72, 830-838. doi:10.1037/0022-006X.72.5.830

Whitton, S. W., Stanley, S. M., Markman, H. J., \& Baucom, B. R. (2008). Women's weekly relationship functioning and depressive symptoms. Personal Relationships, 15, 533-550. doi:10.1111/j.1475-6811.2008 .00214.x

Wolf, A. P., \& Gates, H. (1998). Modeling Chinese marriage regimes. Journal of Family History, 23, 90-99. doi:10.1177/ 036319909802300105

Received December 18, 2012

Revision received January 28, 2013 Accepted April 8, 2013 